\title{
Antiretroviral treatment adherence and associated factors among people living with HIV in developing country, Myanmar
}

\author{
Mya Thandar ${ }^{1}$, Aye Sandar Mon ${ }^{2}$, Suwanna Boonyaleepun ${ }^{3}$, Wongsa Laohasiriwong $^{4} *$
}

\begin{abstract}
${ }^{1}$ Department of Occupational and Environmental Health, University of Public Health, Yangon, Myanmar
${ }^{2}$ Department of Biostatistics and Population Demography, University of Public Health, Yangon, Myanmar

${ }^{3}$ Faculty of Nursing, Khon Kaen University, Khon Kaen, Thailand

${ }^{4}$ Faculty of Public Health, Khon Kaen University, Khon Kaen, Thailand
\end{abstract}

Received: 16 April 2016

Accepted: 25 April 2016

\section{*Correspondence:}

Dr. Wongsa Laohasiriwong

E-mail: drwongsa@gmail.com

Copyright: (C) the author(s), publisher and licensee Medip Academy. This is an open-access article distributed under the terms of the Creative Commons Attribution Non-Commercial License, which permits unrestricted non-commercial use, distribution, and reproduction in any medium, provided the original work is properly cited.

\begin{abstract}
Background: The provision of antiretroviral therapy (ART) has been started in Myanmar, since 2005 by both public and private sectors. Adherence is one of the major critical issues in the clinical management of HIV-infected patients receiving ART. This study aims to determine the level of adherence to ART and possible associated factors in public ART centers, Yangon Region, Myanmar.

Methods: MT his cross-sectional analytical study was conducted between May to July 2015. A total of 425 people living with HIV (PLHIV) were interviewed with pretested structured questionnaires. The multi-method tools were used to access the level of ART adherence. The generalized estimating equation (GEE) model and multiple logistic regression models were administered to determine the possible associated factors to ART adherence.

Results: Only 76.24\% (95\% CI=72.17-80.29) of the respondents had optimal ART adherence ( $\geq 95 \%)$. The respondents of aged more than 40 years were unlikely to adhere ART when compared with younger age $(\mathrm{AOR}=0.01$, 95\% $\mathrm{CI}=0.003-0.05$ ). Those patients who had not satisfied with ART provider services ( $\mathrm{AOR}=0.04,95 \% \mathrm{CI}=0.02$ 0.12 ) were also significantly less likely adhering to ART. However, non-smokers and being taking regular exercise were found to be more likely to adhere to ART.

Conclusion: About a quarter of the PLHIV had suboptimal ART adherence. The older age group and poor patientprovider relationship were found to be the barrier to ART adherence.
\end{abstract}

Keywords: Treatment for HIV/AIDS, Antiretroviral therapy adherence, Myanmar

\section{INTRODUCTION}

Acquired immunodeficiency syndrome (AIDS) is one of the best known chronic diseases that needs daily medications provided by healthcare system of different regions of the world in order to control the associated complication and maintain good health. ${ }^{1}$ Although the clinical outcomes of HIV infected patients have been improved by ART, maintaining an optimal adherence to ART is a great challenge. ${ }^{2}$ Moreover, adverse effects of ART, complexity of the dosing and socio-economic factors also contribute the challenges to the patients and often influence the ART adherence. ${ }^{3}$ Optimal adherence to ART suppresses the viral replication and less likelihood of transmission of HIV to uninfected persons. Furthermore it can reduce morbidity, mortality, also health care costs for PLHIV and also related to the quality of life of those patients. ${ }^{4-7}$ However, almost one third of patients has been missing their doses for ART every 5 days and ART adherence remains a great challenge for many persons receiving ART, and thus the benefits and outcomes of ART are not fully accomplished..$^{8-10}$

Treatment adherence is the quality of sticking to particular instructions by the health care provider including to follow dietary instructions, clinic appointments and lifestyle adjustment. That is why 
adhere to ART is a very complex and dynamic phenomenon which involves the patients, health care providers, the health system within which they operate. ${ }^{11}$ Adherence rate of up to 95 percent is necessary for HIV viral suppression and with 80 percent of adherence can maintain the viral load undetectable over six months. ${ }^{12}$ Therefore, accurate and reliable measures of ART adherence and better understanding of the influencing factors on adherence are essential for clinicians to identify patients who need assistance for taking pills, to develop and evaluate effective interventions to enhance adherence, and to evaluate clinical outcomes and making treatment decisions. ${ }^{13}$

In Myanmar, AIDS is one of the diseases of National concern. The ART provision has started since 2005 and has covered 139 ART Centers/sites including government hospitals and AIDS/STD clinics in public sectors. The number of PLHIVs is estimated about 198,811 for 2013. About 75,000 AIDS patients have been treated for ART in 2014 through coordinated efforts of fifteen implementing partners. According to the fourth edition of National guidelines for the clinical management of HIV infection, with the eligible criteria of $\mathrm{CD}_{4}$ count $<500$, the need for ART in Myanmar is estimated to be more than 120,000 in 2014.

Myanmar has planned to scale up for over 100,000 patients in 2015 and over 111,000 patients by the end of 2016. In order to achieve the ambitious scale up plan, the National AIDS Program has started countrywide ART decentralization since 2013 and has a plan to cover over 100 townships by the end of 2015, with the aim of expanding area coverage, decongestion of ART center work load and improve accessibility for community by reducing the travel time and costs. ${ }^{14}$ Although a few studies had been undertaken on ART adherence in different sites of Myanmar, published literature focusing on adherence to ART and its determinants were limited. $^{15-16}$

This study aims to determine the level of adherence to ART and possible associated factors to provide the baseline data for policy makers in ART provision and adherence counseling services and decentralization of ART plan in Myanmar.

\section{METHOD}

This cross-sectional analytical study was conducted at all public ART centers of Yangon Region. The study populations were PLHIVs attending the outpatient department of the ART centers and receiving ART with first line drugs between May and July 2015. Those patients who gave informed consent, aged 18 years and above and have been taking ART for at least 3 months were eligible for this study. The PLHIVs attending at the prison ART center and those patients who cannot communicate properly because of ill health were excluded in this study.
The sample size was estimated based on the multiple logistic regressions formula ${ }^{17}$ and was calculated by PASS software version 13. Although the calculated sample size was 204, the calculated sample size was multiplied by inflation factor to avoid the clustering effect. Therefore the final samples to be collected were 425. Yangon Region was selected as the study area because of being the largest ART center and HIV/AIDS hospitals are situated in Yangon. There were altogether 9 public ART centers in Yangon Region. Apart from prison ART center, 5 percent of the total attendees from each center were recruited to get the required sample size. The data was collected on the OPD days of each ART center. The eligible samples were selected by applying systematic random sampling from the OPD register book on the day of data collection.

Assessment of ART adherence was carried out by using multi-method tools validated for assessing the ART medication adherence of adult HIV infected patients in resource-constrained setting 18 which consists of self report, visual analogue scale (VAS), pill identification test (PIT) and pill count method. The participants had to answer four questions in self-report form. The questions include patient's recall for any missed dose in the past four days, whether the patient had difficulty to remember to take the medication, any drug holidays and stopping the drug because of side effects. The answer was Yes or No. The answer of No to all questions was scored as high adherence and yes to one question and two or more questions were scored as moderate and low adherence respectively.

Regarding visual analogue scale, the participants had to recall back over the past four days and identified the number of times if he or she either missed a dose or took it at the wrong time. A line with 10 marks from 1 to 10 was drawn and the participants had to mark with a cross on it according to their medication doses that they had taken in the past 4 days. If he or she had taken all medicine doses to point to 10 and if the participants missed all the doses, he or she would point to 0 . The percentage adherence would be 40 percent if the scale was marked at 4 . The results of VAS were scored as high adherence (95\% and more), moderate adherence (75\% to $94 \%)$ and low adherence $(<75 \%)$.

In pill identification test, each patient was asked to show his or her issued medication and checked each container and its contents. He or she had to tell the name of the medication, number of pills have been taken per dose, the time for medication have been taken, and any additional instructions. The scores for (PIT) were high adherence (patients who knew the dose, time for medication and additional instructions), moderate adherence (those who knew only dose and time for medication) and low adherence (those who knew only dose or confused).

Adherence from pill count method was calculated by dividing the difference between the dispensed pills and 
returned pills by the number of pills that have to be taken during the same period. Each patient was asked to recall about the dispensed pills in previous month and returned pills or extra pills when he or she came back for follow up. If leftover medication could not recall, then the calculation was invalid. In this multi-method adherence tool, the overall resultant adherence level was categorized into high level (95\% or more), moderate level (75\% to $94 \%$ ) and low level (less than 75\%). The optimal adherence in this study was considered as adherence of $95 \%$ or more and suboptimal adherence as lower than $95 \%$.

In this study, the dependent variable is ART adherence, which is categorized into optimal and suboptimal. Age, sex, education, occupation, marital status, ART regimen, duration of ART, CD4 count co-morbidities, patient provider relationship, disclosure status, exercise, alcohol drinking and smoking were independent variables.

The data were collected by face-to-face interview with pretested structured questionnaires except self-report form for assessment of ART adherence. Prior to the interview, the questionnaires were translated into Myanmar and back translated into English by an independent translator. One day training was given to four research assistants for data collection about the purpose and facts to follow while asking the questionnaires. All interviews were performed in the separate rooms of the ART centers to ensure privacy and confidentiality. The data were collected after informing about the purpose of the study, risk, benefits and assuring confidentiality to those who were eligible for this study. Immediately after interview, the error, consistency and completeness of the questionnaires were checked to assure the quality of the data. Reviewing of medical records was also done to record the latest CD4 counts and associated co-morbidities.

The data were entered with Epi-data (version 3.1) and analyzed by using the Stata program version 13.0 (Stata Corp, College Station, TX). ART adherence of the participants with $95 \%$ CI was calculated. To determine the factors associated with ART adherence, odds ratios (ORs) and 95\% CI were estimated using multiple logistic regression model. Significant factors in a bivariate analysis with $\mathrm{p}<0.25$ were included in a multiple logistic regression analysis. Since the data collection was conducted at the ART centers; cluster level analysis was performed to adjust for similarities within each center, using the generalized estimating equation (GEE) model. All test statistics were two-sided and a p-value of less than 0.05 was considered as statistical significant.

\section{Ethical consideration}

The Ethical Committee of Khon Kaen University, Thailand had approved this study protocol. Informed consent had taken from all participants prior to interview and all information provided by the participants was confidential and would not be shared to anyone apart from the research team.

\section{RESULTS}

Table 1: Socio-demographic characteristics of the respondents.

\begin{tabular}{|c|c|c|}
\hline \multirow{2}{*}{ Characteristics } & \multicolumn{2}{|c|}{ Total $(n=425)$} \\
\hline & Number & Percentage \\
\hline \multicolumn{3}{|l|}{ Gender } \\
\hline Male & 236 & 55.53 \\
\hline Female & 189 & 44.47 \\
\hline \multicolumn{3}{|l|}{ Age (years) } \\
\hline$\leq 40$ & 203 & 47.76 \\
\hline$>40$ & 222 & 52.24 \\
\hline Mean (SD) & & $41.57(9.62)$ \\
\hline \multicolumn{3}{|l|}{ Marital status } \\
\hline Single & 81 & 19.06 \\
\hline Married & 234 & 55.06 \\
\hline Separate/divorce/widow & 110 & 25.88 \\
\hline \multicolumn{3}{|l|}{ Educational attainment } \\
\hline Illiterate & 6 & 1.41 \\
\hline Can read and write & 8 & 1.88 \\
\hline Primary school & 74 & 17.41 \\
\hline Middle school & 127 & 29.88 \\
\hline High school & 143 & 33.65 \\
\hline University Graduate & 67 & 15.76 \\
\hline \multicolumn{3}{|l|}{ Occupation } \\
\hline Government staff & 29 & 6.82 \\
\hline Private employee & 62 & 40.59 \\
\hline Dependent & 86 & 20.24 \\
\hline Manual labour & 29 & 6.82 \\
\hline Own business & 197 & 46.35 \\
\hline Driver & 22 & 5.18 \\
\hline \multicolumn{3}{|c|}{ Per capita income (MMK)* } \\
\hline$\leq 10,000$ & 358 & 84.24 \\
\hline$>10,000$ & 67 & 15.76 \\
\hline Mean (SD) & 72891.26 & 41.07) \\
\hline \multicolumn{3}{|l|}{ Smoking } \\
\hline Yes & 81 & 19.06 \\
\hline No & 344 & 80.94 \\
\hline \multicolumn{3}{|l|}{ Alcohol consumption } \\
\hline Yes & 32 & 7.53 \\
\hline No & 393 & 92.47 \\
\hline \multicolumn{3}{|l|}{ Taking regular exercise } \\
\hline Yes & 263 & 61.88 \\
\hline No & 162 & 38.12 \\
\hline \multicolumn{3}{|l|}{ Disclosure status } \\
\hline Disclose & 411 & 96.71 \\
\hline Not disclose & 14 & 3.29 \\
\hline
\end{tabular}

(MMK)*: Myanmar currency (Kyats) 
Table 2: Medical history and ART related characteristics.

\begin{tabular}{|c|c|c|}
\hline \multirow{2}{*}{ Characteristics } & \multicolumn{2}{|r|}{ Total $(n=425)$} \\
\hline & Number & Percentage \\
\hline \multicolumn{3}{|l|}{ Duration of ART (months) } \\
\hline$\leq 6$ & 141 & 33.18 \\
\hline$>6$ & 284 & 66.82 \\
\hline Mean (SD) & & $35.09(36.59)$ \\
\hline \multicolumn{3}{|l|}{ Level of knowledge } \\
\hline High & 353 & 83.06 \\
\hline Low & 72 & 16.94 \\
\hline \multicolumn{3}{|l|}{ Missed ART dose in last month } \\
\hline Yes & 26 & 6.12 \\
\hline No & 399 & 93.88 \\
\hline \multicolumn{3}{|l|}{ Reasons for missed ART $(n=26)$} \\
\hline Away from home & 13 & $50.00 \%$ \\
\hline Simply forgot & 15 & $57.69 \%$ \\
\hline Many pills to take & 1 & $3.85 \%$ \\
\hline Medication with social stigma & 1 & $3.85 \%$ \\
\hline \multicolumn{3}{|l|}{ Missed follow up appointment } \\
\hline Yes & 85 & 20.00 \\
\hline No & 340 & 80.00 \\
\hline \multicolumn{3}{|l|}{ Side effect of drugs } \\
\hline Yes & 116 & 27.29 \\
\hline No & 309 & 72.71 \\
\hline \multicolumn{3}{|l|}{ Comorbidities } \\
\hline Yes & 75 & 17.65 \\
\hline No & 350 & 82.35 \\
\hline \multicolumn{3}{|l|}{$\mathrm{CD}_{4}$ count $\left(\mathrm{mm}^{3}\right)$} \\
\hline$<350$ & 186 & 43.76 \\
\hline$\geq 350$ & 239 & 56.24 \\
\hline $\bar{M}$ Mean (SD) & & $415.88(251.36)$ \\
\hline \multicolumn{3}{|c|}{ Travelling time to ART center (minutes) } \\
\hline$<60$ & 130 & 30.59 \\
\hline 60 to 180 & 220 & 51.76 \\
\hline$>180$ & 75 & 17.65 \\
\hline Mean (SD) & & $123.44(132.21)$ \\
\hline \multicolumn{3}{|l|}{ Waiting time at ART center } \\
\hline$<60$ & 28 & 6.59 \\
\hline 60 to 180 & 247 & 58.12 \\
\hline$>180$ & 150 & 35.29 \\
\hline Mean (SD) & & $178.91(91.24)$ \\
\hline \multicolumn{3}{|c|}{ Satisfaction on ART provider service } \\
\hline Yes & 358 & 84.24 \\
\hline No & 67 & 15.76 \\
\hline \multicolumn{3}{|c|}{ Relationship with health care providers } \\
\hline Good & 259 & 60.94 \\
\hline Not good & 166 & 39.06 \\
\hline
\end{tabular}

A total of 425 PLHIVs from 8 public ART centers were recruited for this study. Majority of them were males $(55.53 \%)$ and the mean age was 41.57 with the standard deviation (SD) of 9.62. Married group (55.06\%) constituted more than divorce and widow group $(25.88 \%)$ and single (19.6\%). More than one fourth of the respondents had attained the high school level and nearly half of them $(46.35 \%)$ were self-employed. Nearly one fifth $(19.06 \%)$ of the respondents reported as current smokers and very few $(7.53 \%)$ of them were current alcohol drinkers. More than half $(61.88 \%)$ were reported that they took the physical exercise regularly. Only 14 respondents $(3.29 \%)$ found to be not disclosed their HIV status (Table 1). 
Regarding medical history and ART related characteristics, majority of the patients $(66.82 \%)$ have been taking ART for more than 6 months duration. Most of them $(83.06 \%)$ had high level of ART related knowledge score. Only 26 patients $(6.12 \%)$ had missed their dose of ART one month prior to data collection. The reasons for missed doses were away from home $(50 \%)$, simply forgot $(57.69 \%)$, many pills to be taken $(3.85 \%)$ and medication with social stigma $(3.85 \%)$.

Twenty percent of the participants had missed their follow up appointment at least one time within 3 months prior to data collection. About one forth $(27.29 \%)$ of the respondents mentioned experiencing the side effects of
ART and only (17.65\%) of them had comorbidities. More than half $(56.24 \%)$ had the $\mathrm{CD}_{4}$ count of more than 350 $\mathrm{mm}^{3}$ and the mean $\mathrm{CD}_{4}$ count was 415.88 with SD (251.36). Majority (84.24\%) of the respondents reported that they satisfied with the ART providing services and $60.94 \%$ mentioned that they had good relationship with the health care providers (Table 2).

The level of adherence was assessed by using multimethod tools. Nearly one fourth of the patients $(21.65 \%)$ self-reported that they were difficult to remember to take ART for 4 days recall. Regarding to VAS scores, the ART adherence of more than or equal to $95 \%$ was found to be $(98.35 \%)$.

Table 3: Factors associated with ART adherence using simple logistic regression.

\begin{tabular}{|c|c|c|c|c|c|}
\hline Variable & Total number & Optimal adherence to ART (\%) & Crude OR & $95 \% \mathrm{CI}$ & P-value \\
\hline \multicolumn{5}{|l|}{ Age (years) } & \multirow{3}{*}{$<0.001$} \\
\hline$\leq 40$ & 203 & 61.73 & 1 & & \\
\hline$>40$ & 222 & 38.27 & 0.02 & 0.01 to 0.06 & \\
\hline \multicolumn{5}{|l|}{ Gender } & \multirow{3}{*}{0.04} \\
\hline Male & 236 & 52.78 & 1 & & \\
\hline Female & 189 & 147.22 & 1.62 & 1.02 to 2.56 & \\
\hline \multicolumn{5}{|c|}{ Per capita income (MMK) } & \multirow{3}{*}{0.01} \\
\hline$\leq 10,000$ & 358 & 81.79 & 1 & & \\
\hline$>10,000$ & 67 & 18.21 & 2.59 & 1.19 to 5.62 & \\
\hline \multicolumn{5}{|l|}{ Duration of ART } & \multirow{3}{*}{0.01} \\
\hline$\leq 6$ months & 141 & 36.42 & 1 & & \\
\hline$>6$ months & 284 & 63.58 & 0.51 & 0.31 to 0.86 & \\
\hline \multicolumn{5}{|c|}{ Side effect of drugs } & \multirow{3}{*}{0.05} \\
\hline No & 116 & 75.31 & 1 & & \\
\hline Yes & 309 & 24.69 & 0.62 & 0.38 to 1.00 & \\
\hline \multicolumn{5}{|l|}{ Comorbidities } & \multirow{3}{*}{0.22} \\
\hline Yes & 75 & 16.36 & 1 & & \\
\hline No & 350 & 83.64 & 1.42 & 0.82 to 2.48 & \\
\hline \multicolumn{5}{|c|}{ Travelling time to ART center } & \multirow{4}{*}{0.21} \\
\hline$<60$ minutes & 130 & 32.10 & 1 & & \\
\hline 60 to 180 minutes & 220 & 49.38 & 0.67 & 0.39 to 1.12 & \\
\hline$>180$ minutes & 75 & 18.52 & 1.00 & 0.49 to 2.04 & \\
\hline \multicolumn{5}{|c|}{ Satisfaction on ART provider service } & \multirow{3}{*}{$<0.001$} \\
\hline Yes & 358 & 95.37 & 1 & & \\
\hline No & 67 & 4.63 & 0.05 & 0.02 to 0.09 & \\
\hline \multicolumn{5}{|c|}{ Relationship with healthcare providers } & \multirow{3}{*}{0.08} \\
\hline Good & 259 & 63.27 & 1 & & \\
\hline Bad & 166 & 36.73 & 0.67 & 0.42 to 1.05 & \\
\hline \multicolumn{5}{|l|}{ Smoking } & \multirow{3}{*}{$<0.001$} \\
\hline Yes & 81 & 12.35 & 1 & & \\
\hline No & 344 & 87.65 & 4.85 & 2.89 to 8.14 & \\
\hline \multicolumn{5}{|c|}{ Alcohol consumption } & \multirow{3}{*}{0.03} \\
\hline Yes & 32 & 5.86 & 1 & & \\
\hline No & 393 & 94.14 & 2.37 & 1.13 to 4.99 & \\
\hline \multicolumn{5}{|l|}{ Taking exercise } & \multirow{3}{*}{$<0.001$} \\
\hline No & 263 & 25.62 & 1 & & \\
\hline Yes & 162 & 74.38 & 10.43 & 6.11 to 17.79 & \\
\hline
\end{tabular}


Table 4: Adjusted odds ratio (AOR) of the factors that were associated with ART adherence and their $95 \%$ CI.

\begin{tabular}{|c|c|c|c|c|c|c|}
\hline Variable & Total number & Optimal adherence to ART (\%) & Crude OR & Adjusted OR & $95 \% \mathrm{CI}$ & P-value \\
\hline \multicolumn{7}{|c|}{ Age (years) } \\
\hline$\leq 40$ & 203 & 61.7 & 1 & 1 & \multirow{2}{*}{0.003 to 0.05} & \multirow{2}{*}{$<0.001$} \\
\hline$>40$ & 222 & 38.27 & 0.02 & 0.01 & & \\
\hline \multicolumn{7}{|c|}{ Side effect of drugs } \\
\hline No & 116 & 75.31 & 1 & 1 & \multirow{2}{*}{$\begin{array}{l}0.23 \text { to } \\
1.16\end{array}$} & \multirow{2}{*}{0.11} \\
\hline Yes & 309 & 24.69 & 0.62 & 0.52 & & \\
\hline \multicolumn{7}{|c|}{ Satisfaction on ART provider service } \\
\hline Yes & 358 & 95.37 & 1 & 1 & \multirow{2}{*}{$\begin{array}{l}0.02 \text { to } \\
0.12\end{array}$} & \multirow{2}{*}{$<0.001$} \\
\hline No & 67 & 4.63 & 0.05 & 0.04 & & \\
\hline \multicolumn{7}{|l|}{ Smoking } \\
\hline Yes & 81 & 12.35 & 1 & 1 & \multirow{2}{*}{$\begin{array}{l}1.92 \text { to } \\
9.44\end{array}$} & \multirow{2}{*}{$<0.001$} \\
\hline No & 344 & 87.65 & 4.85 & 4.26 & & \\
\hline \multicolumn{7}{|c|}{ Taking exercise } \\
\hline No & 263 & 25.62 & 1 & 1 & \multirow{2}{*}{$\begin{array}{l}4.87 \text { to } \\
22.04\end{array}$} & \multirow{2}{*}{$<0.001$} \\
\hline Yes & 162 & 74.38 & 10.43 & 10.36 & & \\
\hline
\end{tabular}

Three hundred and twenty four participants $(76.24 \%)$ could identify the name of the medication, the correct number of pills had been taken per dose, the time for medication had been taken and additional instruction concerning food and water intake. According to the overall resultant adherence level, those with optimal adherence $(95 \%$ or more) were $(76.24 \%, 95 \% \mathrm{CI}=72.17$ 80.29, $\mathrm{n}=324)$.

Multivariate analysis after adjusting the clustering effect with GEE found that the respondents of aged more than 40 years were unlikely to adhere ART when compared with younger age $(\mathrm{AOR}=0.01,95 \% \mathrm{CI}=0.003-0.05)$. Those patients who had not satisfied with ART provider services $(\mathrm{AOR}=0.04,95 \% \quad \mathrm{CI}=0.02-0.12)$ were also significantly less likely adhering to ART. Non-smokers $(\mathrm{AOR}=4.26,95 \% \mathrm{CI}=1.92-9.44)$ and being taking regular exercise $\quad(\mathrm{AOR}=10.36, \quad 95 \% \quad \mathrm{CI}=4.87-22.04) \quad$ were significantly more likely to adhere to ART (Table 4).

\section{DISCUSSION}

Adherence usually refers to dose adherence in most studies. However adherence in this study was assessed not only by dose adherence but also scheduling and dietary instructions and then over all resultant adherence was taken into account to consider the level of adherence. The overall adherence level in this study was $76.24 \%$, which was a bit disparity with previous studies $75 \%{ }^{15}$ and $85 \%{ }^{16}$ conducted in Yangon Region. In fact the level of adherence in this study was rather higher than other studies across the South East Asia Region where ART adherence varied widely from $57 \%$ to $75 \%{ }^{19-21}$ and the study undertaken in developed country like Latin America, reported the ART adherence as 55\%. ${ }^{22}$ This may be due to the differences in timing of the study, different measuring tools to assess the adherence level, different settings, and nature of availability of the drugs. Hence comparing the adherences to ART across the studies had to be done with caution. The reasons for missing their medication doses in current study were away from home, forgetfulness, pills overload and medication with social stigma, which were consistent with previous literature. ${ }^{23}$ Because of the self-stigma, the patients dared not taking ART in the presence of others leading to missed doses. A number of studies have been examined for the factors that associated with ART adherence among PLHIV receiving antiretroviral therapy, while some focused on socio-demographic characteristics such as age, gender, education and income, others concentrated on health behavior and cultural beliefs of patients, some emphasized on the patient-provider relationship. The respondents of more than 40 years of age were significantly less likely to adhere ART in this study although several studies reported that there is no consistent correlation between demographic characteristics and level of adherence. ${ }^{24,25}$ Many potentially debilitating adverse effects of ART have also been shown to contribute to irregular taking of the drugs and deliberately stopping of medication by some patients. ${ }^{26}$ The results of current study revealed that the side effect of ART was not associated with ART adherence. This could be the reporting of the respondents being experiencing side effects of ART from both optimal and sub optimal adherence groups. In this study, lack of satisfaction on ART provider services significantly influenced the optimal adherence. Patient's satisfaction is achieved by good patient-provider relationship and more confidence in the provider resulting good adherence. Being non-smokers and those who took regular exercise were strong relationship to optimal adherence. These findings were consistent with the study conducted in Lao PDR. ${ }^{27}$ This may be due to the attitude and adopted life style of the patients.

There were a number of limitations in our study because of its cross-sectional design and assessed the ART adherence at a single time point. In fact, it was impossible 
to evaluate variations in adherence over time and the extent of generalizability is limited only to those similar patients. Because of cross-sectional nature of the study, it did not allow the cause and effect relationships between various factors and adherence to be addressed. Despite the limitation, this finding was useful for program managers as a base line to develop appropriate strategies to address the issue of adherence from both the clinician and the patient side.

\section{CONCLUSION}

In conclusion, the level of adherence in present study was relatively higher than other studies conducting in South East Asia. The older age group and lack of patient's satisfaction were found to be the barriers to ART adherence. Being non-smoker and taking regular exercise were significantly associated with optimal adherence.

Funding: No funding sources

Conflict of interest: None declared

Ethical approval: The study was approved by the Institutional Ethics Committee

\section{REFERENCES}

1. Volberding PA, Deeks SG. Antiretroviral therapy and management of HIV infection. The Lancet. 2010;376(9734):49-62.

2. Wang H, Zhou J, He G, Luo Y, Li X, Yang A. Consistent ART adherence is associated with improved quality of Life, $\mathrm{CD}_{4}$ counts, and reduced hospital costs in central China. AIDS Research and Human Retroviruses. 2009;25(8):757-63.

3. Amberbir A, Woldemichael K, Getachew S, Girma B, Deribe K. Predictors of adherence to antiretroviral therapy among HIV-infected persons: a prospective study in Southwest Ethiopia. BMC Pub Health. 2008;8:265.

4. Palella FJ, Delaney KM, Moorman AC, Loveless MO, Fuhrer J, Satten GA, et al. Declining morbidity and mortality among patients with advanced human immunodeficiency virus infection. HIV Outpatient Study Investigators. New England J Med. 1998;338(13):853-60.

5. Rathbun RC, Lockhart SM, Stephens JR. Current HIV treatment guidelines: an overview. Current Pharmaceutical Design. 2006;12(9):1045-63.

6. Mannheimer SB, Matts J, Telzak E, Chesney M, Child $\mathrm{C}, \mathrm{Wu} \mathrm{AW}$, et al. Quality of life in HIVinfected individuals receiving antiretroviral therapy is related to adherence. AIDS Care. 2005;17(1):1022.

7. M D, As F, Jg B, Je K, Ak P. Guidelines for using antiretroviral agents among HIV-infected adults and adolescents. Recommendations of the Panel on Clinical Practices for Treatment of HIV. MMWR Recommendations and Reports: Morbidity and Mortality Weekly Report. Recommendations and
Reports/Center of Disease Control. 2002;51(RR7):1-55.

8. Phillips JC. Antiretroviral therapy adherence: testing a social context model among Black men who use illicit drugs. J Assoc Nurs AIDS Care. 2011;22(2):100-27.

9. Catz SL, Kelly JA, Bogart LM, Benotsch EG, McAuliffe TL. Patterns, correlates, and barriers to medication adherence among persons prescribed new treatments for HIV disease. Health Psychology: official journal of the division of health psychology. American Psychological Association. 2000;19(2):124-33.

10. Protopopescu C, Raffi F, Roux P, Reynes J, Dellamonica P, Spire B et al. Factors associated with non-adherence to long-term highly active antiretroviral therapy: a 10 year follow-up analysis with correction for the bias induced by missing data. J Antimicrob Chemother. 2009;64(3):599-606.

11. Miller CM, Ketlhapile M, Rybasack-Smith H, Rosen S. Why are antiretroviral treatment patients lost to follow-up? A qualitative study from South Africa. Trop Med Intern Health. 2010;15(s1):48-54.

12. Paterson DL, Swindells S, Mohr J, Brester M, Vergis EN, Squier C, et al. Adherence to protease inhibitor therapy and outcomes in patients with HIV infection. Annal of Intern Med. 2000;133(1):21-30.

13. Laurence $\mathrm{J}$, ed. Medication Adherence in HIV/AIDS. 1 edition. Larchmont, NY: Mary Ann Liebert Inc; 2004:396.

14. MOH. Health in Myanmar 2015. 2015. Available at http://www.moh.gov.mm/. Accessed on 20 March 2016.

15. New TW. Antiretroviral therapy adherence among people living with HIV/AIDS in public and INGO centers, Yangon. 2013.

16. Thar K. Study of AIDS patients treated with Antiretroviral Therapy in Wai-Bargi Specialist Hospital, Yangon. 2005.

17. Hsieh FY, Bloch DA, Larsen MD. A simple method of sample size calculation for linear and logistic regression. Statistics in Medicine. 1998;17(14):1623-34.

18. Steel G, Nwokike JP, Joshi M. Development of a multi method tool to measure art adherence in resource-constrained settings: the South Africa Experience. USAID. 2007;61.

19. Sujipittham. Factors affecting adherence to ART regimens among HIV-infected/AIDS-patients at Taksin Hospital. 2012.

20. Rai S, Mahapatra B, Sircar S, Raj PY, Venkatesh S, Shaukat M, et al. Adherence to Antiretroviral Therapy and Its Effect on Survival of HIV-Infected Individuals in Jharkhand, India. Plos One. 2013;8(6):e66860.

21. Kumar A, Alandikar V, Mhaskar R, Emmanuel P, Djulbegovic B, Patel S, et al. Adherence to antiretroviral therapy in India: a systematic review and meta-analysis. Indian $\mathbf{J}$ of Community Med. 2013;38(2):74. 
22. Mills EJ, Nachega JB, Buchan I, Orbinski J, Attaran A, Singh S, et al. Adherence to antiretroviral therapy in sub-Saharan Africa and North America: a meta-analysis. JAMA. 2006;296(6):679-90.

23. Uzochukwu BSC, Onwujekwe OE, Onoka AC, Okoli C, Uguru NP, Chukwuogo OI. Determinants of non-adherence to subsidized anti-retroviral treatment in southeast Nigeria. Health Policy and Planning. 2009;24(3):189-96.

24. Rougemont $M$, Stoll BE, Elia N, Ngang $P$. Antiretroviral treatment adherence and its determinants in Sub-Saharan Africa: a prospective study at Yaounde Central Hospital, Cameroon. AIDS Research Therapy. 2009;6(1):21.

25. Cauldbeck MB, O'Connor C, O'Connor MB, Saunders JA, Rao B, Mallesh VG, et al. Adherence to anti-retroviral therapy among HIV patients in
Bangalore, India. AIDS Research Therapy. 2009;6:7.

26. Waters L, Nelson M. Why do patients fail HIV therapy? International Journal of Clinical Practice. 2007;61(6):983-90.

27. Hansana, V, Sanchaisuriya P, Durham J, Sychareun, V, Chaleunvong K, Boonyaleepun S, Schelp FP. Adherence to antiretroviral therapy among people living with HIV: a cross-sectional survey to measure in Lao PDR. BMC Public Health. 2013;13(1):617.

Cite this article as: Thandar M, Mon AS,

Boonyaleepun S, Laohasiriwong W. Antiretroviral treatment adherence and associated factors among people living with HIV in developing country, Myanmar. Int J Community Med Public Health 2016;3:1318-25. 